\title{
INTERACTION OF TIARAMIDE HYDROCHLORIDE WITH AMBERLITE RESINS: CHARACTERIZATION OF THE INTERACTION AND MODULATION OF THE RELEASE THROUGH MICROENCAPSULATION OF THE PREPARED RESINATES
}

M. Fathy

Department of Pharmaceutics, Faculty of Pharmacy, Assiut University 71526, Assiut, Egypt

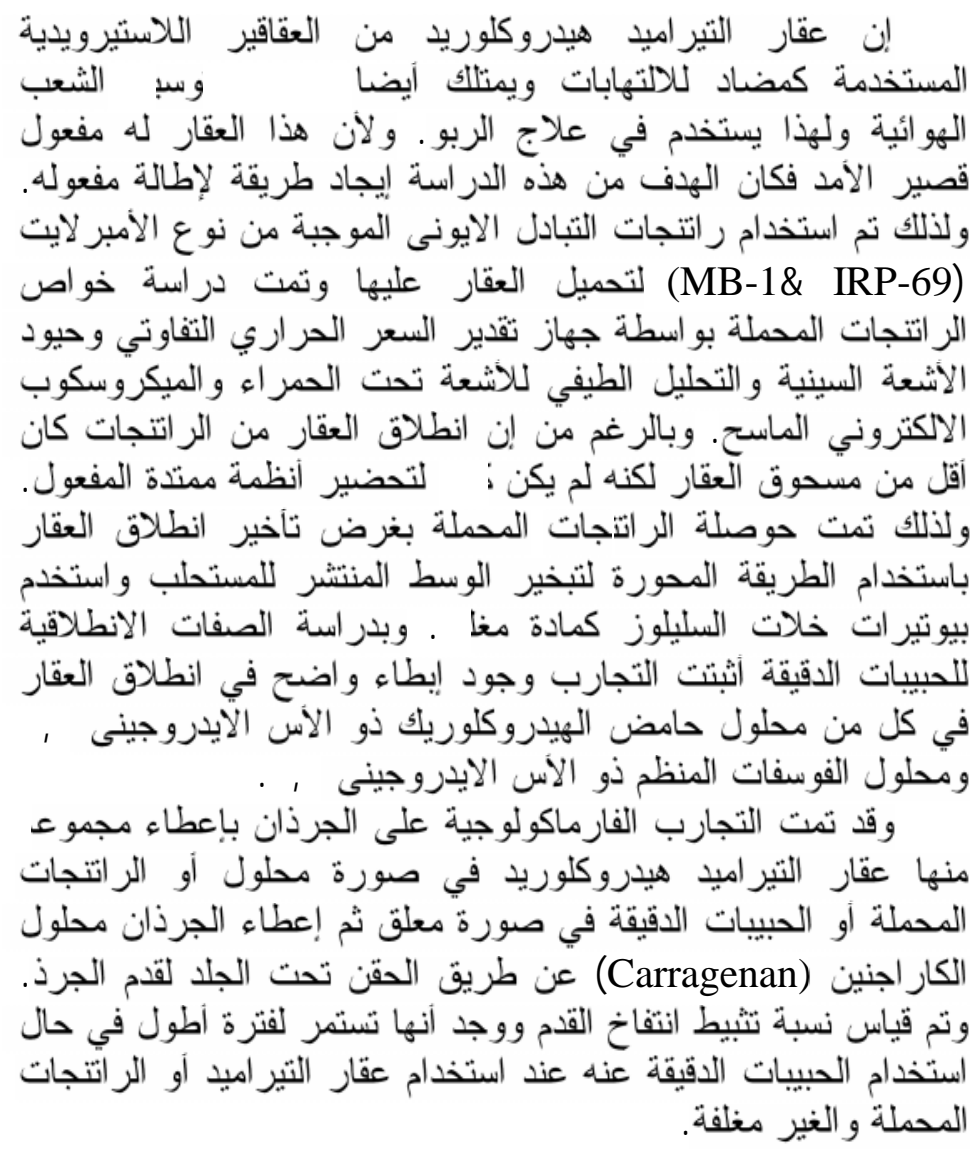

Received in 28/12/2005 \& Accepted in 9/4/2006

Corresponding author E-mail address: Fathy@mailcity.com 
Tiaramide $\mathrm{HCl}$ (TAM), a basic NSAID, has high water solubility and short biological half life. The study was undertaken to prolong TAM's activity. TAM resinates were prepared by a batch process and using two resins, namely Amberlite IRP-69 (RI) and Amberlite MB-1 (RII). The resinates (RI/TAM \& RII/TAM) were examined by differential scanning calorimetry (DSC), X-ray powder diffraction (XRD), infrared (IR) spectrometry and scanning electron microscopy (SEM). A modified emulsion solvent evaporation method was used to produce TAM-resinates coated with cellulose acetate butyrate $(C A B)$ for more drug retardation. The microcapsules were examined using SEM. The results from DSC and XRD showed that the molecular state of the drug in the resinates changed to become amorphous instead of its original crystalline form. The IR spectroscopy revealed the presence of an interaction between the drug and resin. The dissolution behavior for the resinates in $0.1 \mathrm{~N} \mathrm{HCl}$ or phosphate buffer ( $p H$ 7.4) was compared. TAM release was affected by the dissolution medium and resin type and was slower than that from drug powder or physical mixture. TAM release from microcapsules was slower than the uncoated resinates. Additionally, the anti-inflammatory activity, using carrageenan-induced rat hind paw edema, displayed prolonged pattern in comparison with uncoated resinate or free drug

\section{INTRODUCTION}

The ion exchange resins are crosslinked water-insoluble polymer carrying ionizable functional groups. Drugs can be loaded onto the resins by an exchanging reaction, and hence a drug-resin complex (drug resinate) is formed. ${ }^{1}$ Some pharmaceutical properties of a drug prepared as a drug-resin complex are modified from pure drug including decrease drug release, taste, toxicity and stability enhancement of the drug. ${ }^{2-4}$ Resinates of drugs can be formulated as sustained-release suspension, ${ }^{5}$ tablets $^{6 \& 7}$ and microparticles. ${ }^{8}$ Moreover, the coating of the complex with some polymers has been claimed to change some of these properties more than the uncoated complex. . $^{-11}$ Formulation and preparation parameters of drug/ion-exchange particles microencapsulated in crosslinked chitosan were evaluated for controlled release of the water-soluble drug chlorpheniramine maleate in a suspension. ${ }^{8}$ Coated ion-exchange system for phenylpropanolamine ${ }^{12}$ and sulfonic acid resins loaded with dextromethorphan ${ }^{13}$ were reported to obtain sustain release drug delivery systems. Similarly, coating of pseudoephedrine-dowex 50 WX8 complexes with carnauba wax for sustained release has been reported. ${ }^{14}$ 
Polyethyleneimine-treated calcium alginate beads loaded with the resinate were prepared by an ionic/polyelectrolyte complexation method and the effect of different formulation variables on the characteristics of the beads was investigated to develop a multi-unit sustained release dosage form of diltiazem. ${ }^{15}$

Tiaramide hydrochloride, 4-[(5chloro-2-oxo-3-benzothiazolinyl)

acetyl] -1-piperazine ethanol hydrochloride (Figure 1), is a basic NSAID and possesses analgesic and antipyretic properties. ${ }^{16 \& 17}$ In addition, it is used in treatment of bronchial asthma because it has antianaphylactic and bronchodilatory effect. ${ }^{18}$ The plasma level of tiaramide elevated to a peak within one hour and declined linearly with a half-life of about 2 hours. ${ }^{19}$ Hence, it would be beneficial if it is formulated in prolonged release dosage form.

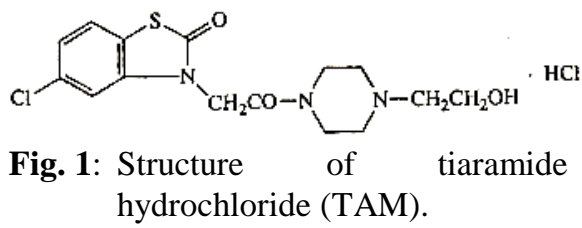

Therefore, this work was carried out to investigate the molecular state of TAM prepared as resinates using differential scanning calorimetry (DSC), X-ray powder diffraction (XRD), infrared spectroscopy (IR) and scanning electron microscopy (SEM). Then, the resinates were subjected to microencapsulation with cellulose acetate butyrate using modified emulsion-solvent evaporation technique for more drug retardation. The dissolution of TAM from the prepared microcapsules was tested in vitro in $0.1 \mathrm{~N} \mathrm{HCl}$ and phosphate buffer ( $\mathrm{pH}$ 7.4) and their anti-inflammatory activity was evaluated using acute rat paw edema.

\section{EXPERIMENTALS}

\section{Materials}

Tiaramide HCL was obtained from Fujisawa Pharm. Co., Ltd. Osaka, Japan. Amberlite IRP-69 (Sodium form) \& Amberlite MB-1 (Hydrogen form) were received from Aldrich Chem. Comp., Inc., Milwaukee, W.S., USA. Cellulose acetate butyrate was provided by FMC Co., USA. Deionized water was used throughout the study. All solvents and reagents were of analytical grade.

$\begin{aligned} & \text { Purification of ion exchange } \\ & \text { resins }\end{aligned}$
$100 \mathrm{ml}$ deionized water was added to the resin $(5 \mathrm{~g},<90 \mathrm{~m})$ placed in an Erlenmeyer flask. The slurry was stirred with a magnetic bar for $30 \mathrm{~min}$ and allowed to settle for $15 \mathrm{~min}$; then, the supernatant was removed by decantation. The resin was washed another two times according to the above procedure. The washed resin was collected by filtration and dried overnight in a hot air oven at $50^{\circ}$. The dried resin was kept in a tight vial until preparation of the resinates. 


\section{Preparation of TAM resinates}

TAM resinates were prepared using a batch process. Resin (1 g, < $90 \mathrm{~m}$ ) was placed in an Erlenmeyer flask and then $50 \mathrm{ml}$ of $2 \% \mathrm{w} / \mathrm{v}$ aqueous TAM solution was added. The mixture was shaken in the water bath at $37^{\circ}$ for $2 \mathrm{~h}$ (equilibrium time $)^{21}$ at 50 stroke/min. Then, the TAM resinates (RI/TAM and RII/TAM) were separated by filtration, and washed several times with deionized water to remove any surface adsorbed drug and other ions. Resinates were dried overnight at $50^{\circ}$ and kept in a desiccator. The amount of free drug in the filtrate as well as the washing water was determined spectrophotometrically at a wavelength of $295 \mathrm{~nm}^{22}$ (Shimadzu-50-02, Japan). Determinations were carried out in duplicate for each batch. The difference in weights between the initial amount of drug added and the remaining amount of drug in the solution was the amount of drug loaded onto the resins.

The physical mixtures (PMs) were prepared with the same drug content of resinates by gentle mixing using pestle and mortar.

\section{Microencapsulation of prepared resinates}

Microcapsules were prepared, at 3:1 resinate: polymer ratio, using modified emulsion solventevaporation method. One gram of resinate was dispersed in solution of cellulose acetate butyrate in acetone $(\mathrm{CAB} ; 0.33 \mathrm{~g}$ as $5 \% \mathrm{w} / \mathrm{v})$. The mixture was poured into vessel containing paraffin oil $(100 \mathrm{ml})$ and span $80(1 \mathrm{ml})$. After emulsification for $15 \mathrm{~min}, 5 \mathrm{ml}$ of $n$-hexane was added dropwise at a constant rate of 1 $\mathrm{ml} / \mathrm{min}$ to precipitate the coat around the resinate particles. Two hours later, the microcapsules were separated by filtration and washed three times with $n$-hexane, then dried in an oven at $50^{\circ}$ for 24 hour. The microcapsules were sized through standard sieves and the fraction size used throughout the study was in the range of 90-250 m since it represented the major fraction of the batch.

Drug content of the microcapsules was determined after pulverization an amount of microcapsules equivalent to $50 \mathrm{mg}$ of drug then the pulverized microcapsules were transferred to 100 $\mathrm{ml}$ volumetric flask with the aid of 1 $\mathrm{N} \mathrm{HCl}$ containing $2 \% \mathrm{NaCl}$. The volume was adjusted and set aside for $24 \mathrm{~h}$. An aliquot was withdrawn, filtered, suitably diluted and assayed spectrophotometrically at $295 \mathrm{~nm}$.

\section{Dissolution study}

The dissolution rate for all the samples was studied using the USP paddle apparatus. The sample was accurately weighed to obtain the equivalent of $50 \mathrm{mg}$ of drug and added to vessels containing $500 \mathrm{ml}$ of dissolution medium $(0.1 \mathrm{~N} \mathrm{HCl}$ or phosphate buffer of $\mathrm{pH}$ 7.4). The temperature and paddle speed were set at $37 \pm 0.1^{\circ}$ and $50 \mathrm{rpm}$, respectively. At suitable time intervals, samples of $5 \mathrm{ml}$ volume were withdrawn and replaced with equal volume of fresh test solution. The drawn samples were filtered and assayed. The amount of drug released 
was analyzed by UV spectroscopy at $295 \mathrm{~nm}$.

The release kinetic of TAM from the resinates was analyzed using particle diffusion-controlled model ${ }^{23}$ as the following equation:

$$
-\ln (1-\mathrm{F})=1.59\left\{6 / \mathrm{d}_{\mathrm{p}}\right\}^{1.3} \mathrm{D}^{0.65} \mathrm{t}^{0.65}
$$

Where $\mathrm{F}$ is fractional release of drug from the resinate, $d_{p}$ is mean particle size of resin, D is apparent diffusion coefficient or diffusivity and $t$ is time. By plotting - $\ln (1-\mathrm{F})$ against $\mathrm{t}^{0.65}$, the slope of this relationship could be calculated using linear regression analysis according to the following equation.

$$
-\ln (1-\mathrm{F})=\mathrm{K} \mathrm{t}^{0.65}
$$

Where $\mathrm{k}$ is the release rate constant.

The release data from microencapsulated resinates were examined according to the common kinetic models (zero-order, first-order, Higuchi square root model). In addition, TAM release data were analyzed through $60 \%$ released using the Ritger and Peppas ${ }^{24}$ equation as follows:

$\mathrm{M}_{\mathrm{t}} / \mathrm{M}_{\infty}=\mathrm{Kt}^{\mathrm{n}}$

Where $M_{t} / M_{\infty}$ represents the fraction of the drug released at time $t, K$ is a constant incorporating structural and geometric characteristics of controlled release device.

\section{Infrared spectroscopy (IR)}

Infrared spectra of the samples were recorded on a Hitachi 295 infrared spectrophotometer (Hitachi,
Japan). The samples were scanned over the range of 4000 to $400 \mathrm{~cm}^{-1}$.

\section{Differential scanning calorimetry (DSC) \\ DSC analysis was carried out on a} differential scanning calorimeter (DSC-50 Shimadzu, Japan) at a heating rate of $10^{\circ}$ per minute in the range of 25 to $350^{\circ}$. Thermal analysis data were recorded using a TA 50I PC system with Shimadzu software programs. The instrument was calibrated with pure indium and the samples (3-5 $\mathrm{mg}$ ) were heated in hermetically sealed aluminum pans.

\section{X-ray diffractometry (XRD)}

X-ray diffraction studies of the samples were performed using an automated X-ray diffractometer (Model FW 1700 series, Philips, Netherlands) with a filter $\mathrm{Ni} \mathrm{C}_{\mathrm{u}} \mathrm{K}_{\alpha}$ radiation detector, voltage $40 \mathrm{kV}$; current $30 \mathrm{~mA}$ and at a scanning rate of $10 \mathrm{~mm} / \mathrm{sec}$.

\section{Scanning electron microscopy (SEM)}

The samples were mounted onto metal stubs using double-sided adhesive tape, vacuum-coated with a layer of gold using a sputter coater (SPI, sputter, USA). The shape, size and surface of the samples were examined with a scanning electron microscope (Joel JSM 5400LV SEM, $15 \mathrm{kV}$, Japan).

\section{Anti-inflammatory study}

Anti-inflammatory studies were carried out in carrageenan-induced rat hind paw edema model. ${ }^{25}$ Five 
male Wistar rats weighing 180-210 g were used per group. The animals were starved for $18 \mathrm{~h}$ but water was allowed ad libitum. Group 1 received saline solution and considered as a control. Group 2 received $200 \mathrm{mg} / \mathrm{kg}$ of pure TAM dissolved in $2 \% \mathrm{w} / \mathrm{v}$ methylcellulose. Group 3 received resinates of IRP-69 in dose 100 $\mathrm{mg} / \mathrm{kg}$ equivalent to TAM, with 100 $\mathrm{mg} / \mathrm{kg}$ of pure TAM in form of solution. Group 4 received microcapsules; prepared at 3:1 resinates IRP-69:CAB, at dose $100 \mathrm{mg} / \mathrm{kg}$ equivalent to TAM, with $100 \mathrm{mg} / \mathrm{kg}$ of pure TAM in form of solution. The samples were administered orally through stomach gavage followed by $1 \mathrm{ml}$ water. One hour later, $0.1 \mathrm{ml}$ of $1 \%$ carrageenan was injected subcutaneously into plantar surface of hind paw and the paw volume (mm) was measured with a dial caliper at 1 , 2, 3, 4, 5, 6 and 7 hours after administration of carrageenan. The foot volume after injection of the inflammatory agent was compared with that before injection and the percent swelling of foot edema was calculated. The percent diminution was computed from difference in percent swelling between the treated group and the control group. ${ }^{25}$

\section{Statistical analysis}

The two-tailed distribution Student's $t$ test was applied to examine significance of differences. In all cases, $P<0.05$ was considered to be significant and highly significant for $P<0.01$.

\section{RESULTS AND DISCUSSION}

The TAM loading of the resinates (RI/TAM) using Amberlite IRP-69 was $41.56 \pm 0.42 \% \mathrm{w} / \mathrm{w}$, while for that (RII/TAM) using Amberlite MB1 was $36 \pm 0.36 \%$ w/w. The difference in the loading reflected the nature of each resin. RI is strong cationic exchanger, while RII is a mixture of strong cations and anions exchanger that fact gave RI more available sites for the exchanging.

\section{Differential scanning calorimetry (DSC)}

Figure 2 displays the DSC curves of the TAM, resins, physical mixtures (PMs) and resinates. Tiaramide has an endothermic peak at $268^{\circ}$,

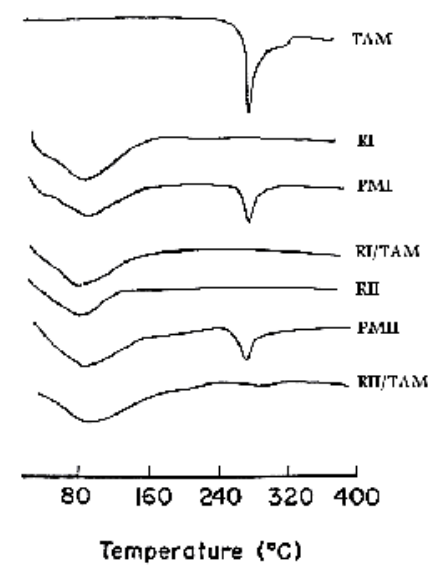

Fig. 2: DSC curves for samples: Tiaramide (TAM); Amberlite IRP-69 (RI); Physical mixture of RI and TAM (PMI); Resinate of RI and TAM (RI/TAM); Amberlite MB-1 (RII); Physical mixture of RII and TAM (PMII); Resinate of RII and TAM (RII/TAM). 
indicating the temperature of drug melting. The thermal trace shown by resins (RI or RII) was characterized by a broad endothermic peak at 90$110^{\circ}$ as a result of the partial dehydration process of the resins. The trace of physical mixtures (PMI or PMII) was representing the simple superimposition of TAM trace and RI or RII trace. This clearly indicated that the preparation of the physical mixture, as well as the heating, caused no interaction between the components. No peak over the range $25-350^{\circ}$ was detected in the DSC curves of the resinates suggesting the presence of resins or drug in the resinates in an amorphous form.

\section{X-Ray diffraction patterns (XRD)}

The XRD patterns of the samples are shown in Figure 3. Tiaramide is highly crystalline drug with characteristic peaks appeared at $\theta$ equal to $15.07,23.93,24.52,26.95$, $27.93^{\circ}$. Physical mixtures show sharp peaks, almost at the same position, indicating that TAM kept its crystalline structure in these preparations. Resins displayed diffused peak due to their amorphous state. Halo' patterns also were given by resinates. DSC and XRD showed that the molecular state of the entrapped drug in the resinates changed from the crystalline to the amorphous state. From this it appeared that the drug was dispersed monomolecularly in the resinates. In the case of physical mixtures, the molecule of drug, which was outside the resin bead, did not disperse monomolecularly, so the crystalline state of the pure drug was presented. ${ }^{20}$

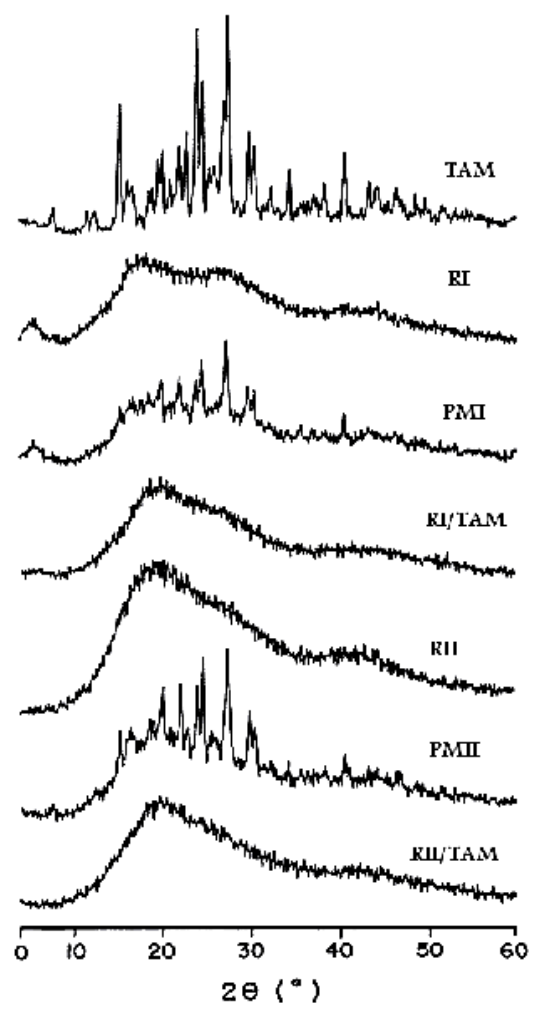

Fig. 3: XRD patterns for the samples: Tiaramide (TAM); Amberlite IRP-69 (RI); Physical mixture of RI and TAM (PMI), Resinate of RI and TAM (RI/TAM), Amberlite MB-1 (RII); Physical mixture of RII and TAM (PMII), Resinate of RII and TAM (RII/TAM).

\section{Infrared spectroscopy (IR)}

Figure 4 demonstrates the IR spectra of the samples. TAM shows the following characteristic absorption bands: $3520 \mathrm{~cm}^{-1}(\mathrm{OH})$, 
$3255 \mathrm{~cm}^{-1}\left(\mathrm{NH}^{+}\right), 1694 \mathrm{~cm}^{-1} \& 1653$ $\mathrm{cm}^{-1} \quad(\mathrm{C}=\mathrm{O}), \quad 1576 \mathrm{~cm}^{-1} \quad(\mathrm{C}=\mathrm{C}$; aromatic). It was observed that the physical mixtures (PMs) did not show any significant change in the position of the absorption bands of characteristic groups. These spectra appeared to be consistent with that of TAM and RI or RII. The result suggested that there was no interaction between the drug and the resin in these mixtures coinciding with the results from DSC and XRD.

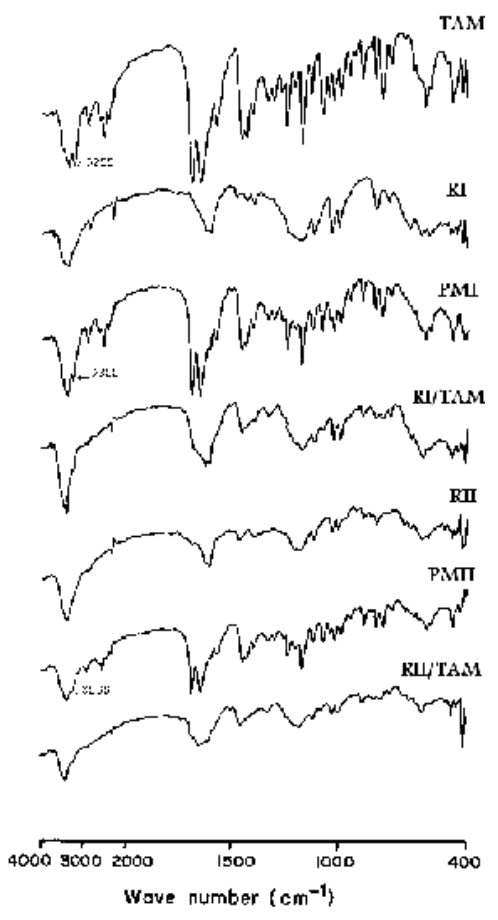

Fig. 4: IR spectra for the samples: Tiaramide (TAM); Amberlite IRP-69 (RI); Physical mixture of RI and TAM (PMI); Resinate of $\mathrm{RI}$ and TAM (RI/TAM); Amberlite MB-1 (RII); Physical mixture of RII and TAM (PMII); Resinate of RII and TAM (RII/TAM).
The spectra of drug-resin complexes in the region of 400-2000 $\mathrm{cm}^{-1}$ showed the existence of major peaks of TAM prevailing the entrapment of TAM in the resinates. Furthermore, the peak of the drug which appeared at $3255 \mathrm{~cm}^{-1}$ which might be assigned to stretching vibration of the $\mathrm{NH}^{+}$group of drug interacting with chloride ion disappeared in the complex spectra. The results could be attributed to an ionic interaction between the $\mathrm{NH}^{+}$ group in TAM and the sulphonate groups in RI or RII. These results were similar to those obtained by Akkaramongkolporn et $a l^{20}$ who showed that chorphenarmine maleate existed in the positively charged form which interacted with the sulphonate group in the resin. Additionally, in another study, it was reported that $\mathrm{NH}_{2}{ }^{+}$group of propranolol which originally bound chloride ion was transformed to interact with the sulfonate group of resin (Amberlite IRP-69) in the complexes. ${ }^{26}$ The interaction of TAM with the resins could be a contributing factor in transformation of the drug to amorphous form. Porubcan et $\mathrm{al}^{27}$ proposed that new chemical bonds and strong complexations could alter the crystalline structure of drug resulting in a changed XRD pattern.

\section{Scanning electron microscopy (SEM) \\ The scanning electron micrographs (SEM) for different samples are presented in Figures 5 and 6. It appeared that the drug crystals were elongated tabular form.}


Both of RI and RII were irregular in shapes and appeared as separate pieces. PMI or PMII observed as a mixture of drug and the resin. It was easy to identify the individual component of TAM with RI or RII in case of PMI or PMII. RI/TAM and
RII/TAM looked different in appearance from the drug, resin or their mixture. The features of drug crystals were not easily detectable indicating formation of different compounds than the individual resin.
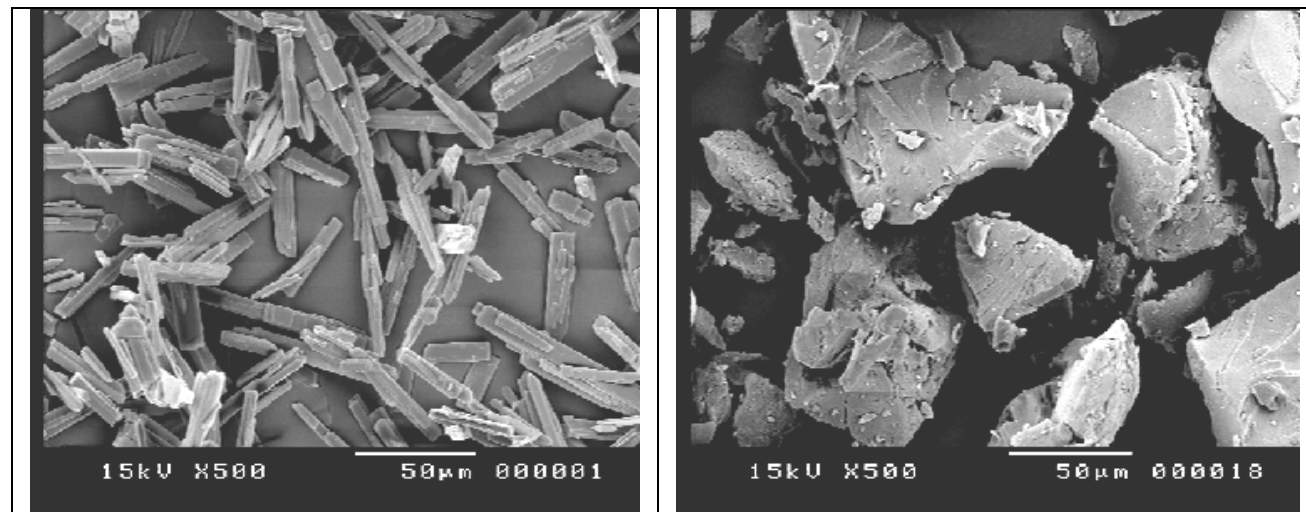

TAM

$\mathbf{R I}$

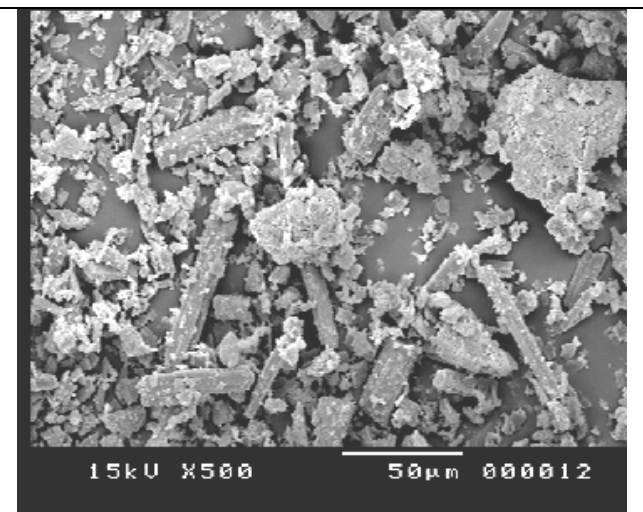

PM I

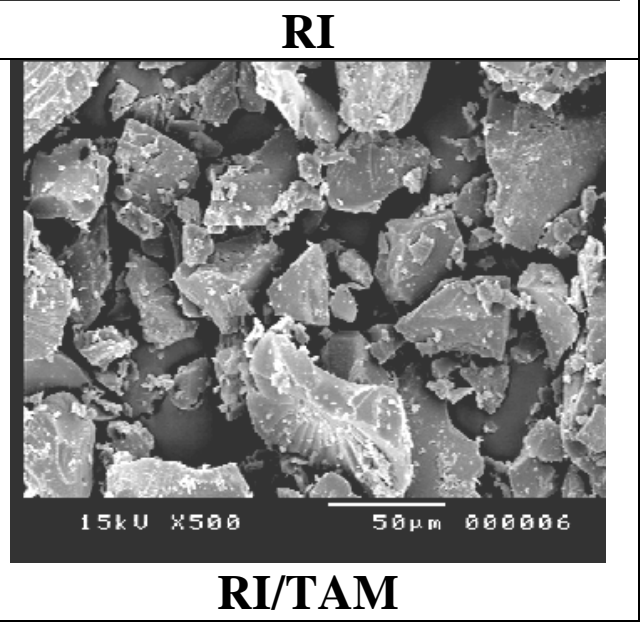

Fig. 5: Scanning electron micrographs for different systems of tiaramide and Amberlite IRP-69: Tiaramide (TAM); Amberlite IRP-69 resin (RI); Physical mixture (PMI); Resinate (RI/TAM). 


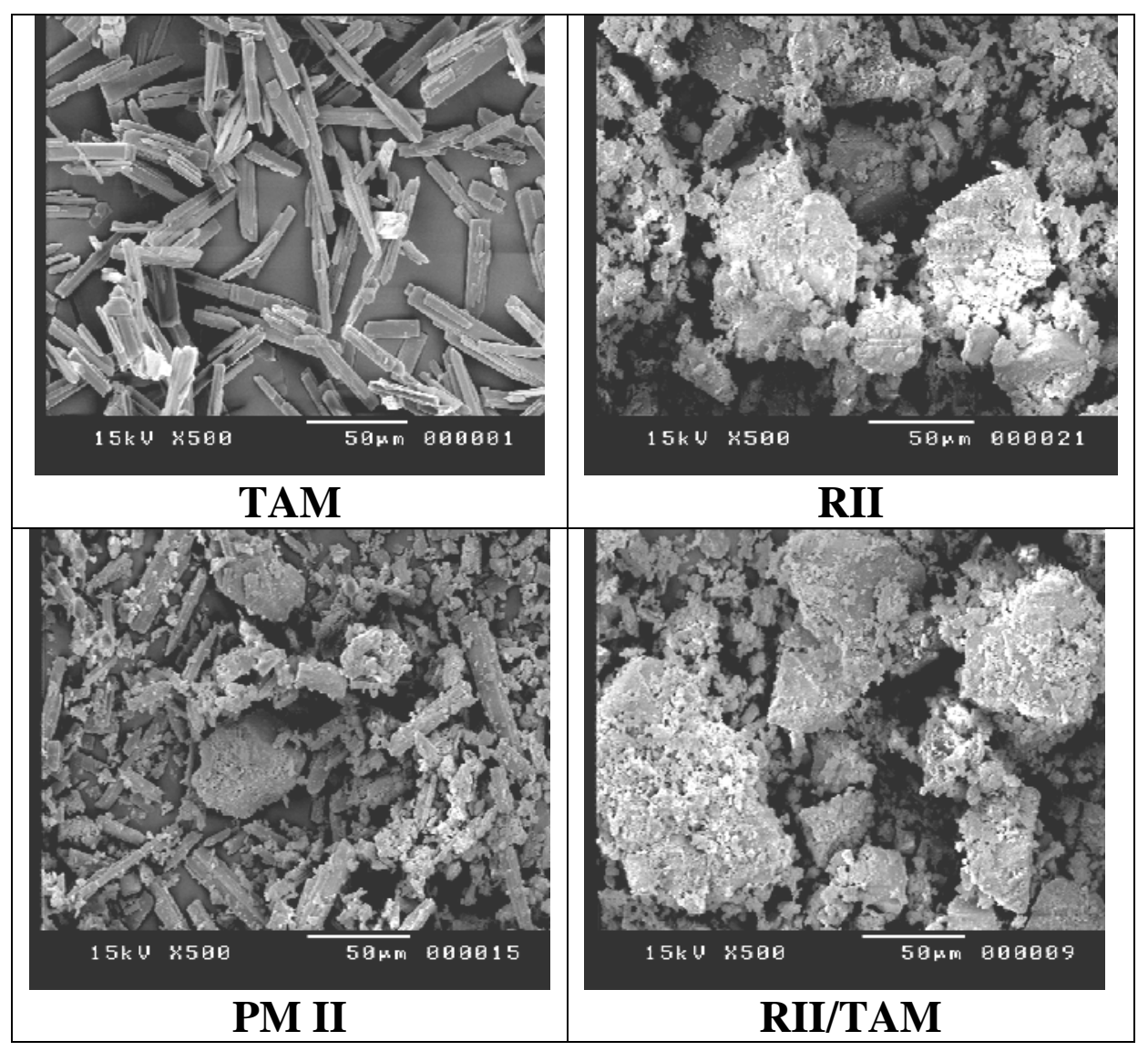

Fig. 6: Scanning electron micrographs for different system of tiaramide and Amberlite MB-1. Tiaramide (TAM); Amberlite MB-1 resin (RII), Physical mixture (PMII) and Resinate (RII/TAM)

\section{Release study from resinates}

The dissolution of the drug, physical mixtures (PMs) and resinates are presented in Figures 7 and 8. The PMI and PMII gave similar release rate to that of the drug suggesting no interaction between resins and TAM in that forms. However, the release rate from the resinates was slower than that of drug or physical mixtures.
The slow release rate in case of the resinates, in spite of the amorphous molecular state of the drug, may be attributed to their crosslinked structure which resists drug diffusion through the resin beads. ${ }^{26}$ This might indicate that the molecular property of drug was not a major determinant of the release behavior of drug from the complexes. In general, the release in 
$0.1 \mathrm{~N} \mathrm{HCl}$ was less than that in $\mathrm{pH}$ 7.4 in spite the higher solubility of TAM in acidic medium, as well as, the cation exchange should occur faster in acidic medium than in phosphate buffer due to the greater affinity for hydrogen ions compared to sodium or potassium ions. However, the results obtained could be presumably inferred from the difference in the concentration of different counter ions in eluting medium. This result also confirmed the presence of the drug with the resins in form of complex and its release was affected by the amount of ions in the dissolution medium.

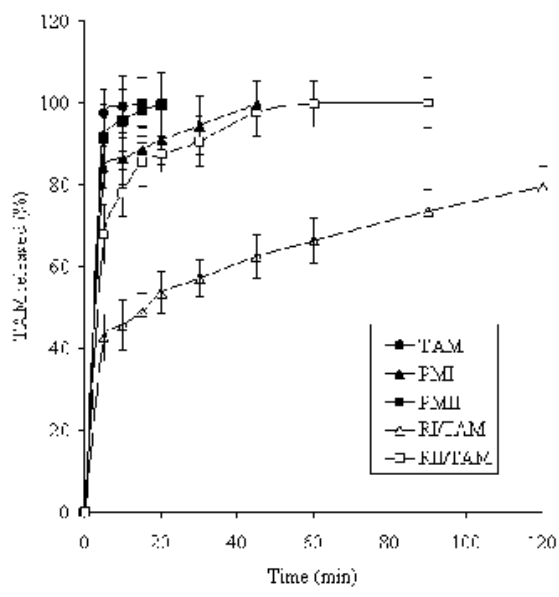

Fig. 7: Dissolution rate for the samples in $0.1 \mathrm{~N} \mathrm{HCl}$ : Tiaramide (TAM); Physical mixture of RI and TAM (PMI); Resinate of RI and TAM (RI/TAM); Physical mixture of RII and TAM (PMII); Resinate of RII and TAM (RII/TAM). Error bars indicates $\mathrm{SD}, \mathrm{n}=3$

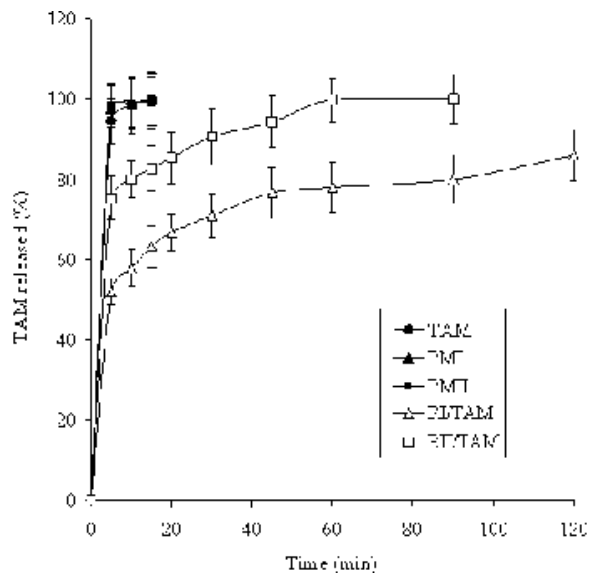

Fig. 8: Dissolution rate for the samples in phosphate buffer ( $\mathrm{pH}$ 7.4): Tiaramide (TAM); Physical mixture of RI and TAM (PMI); Resinate of RI and TAM (RI/TAM); Physical mixture of RII and TAM (PMII); Resinate of RII and TAM (RII/TAM). Error bars indicates $\mathrm{SD}, \mathrm{n}=3$.

The -ln (1-F) had a good correlation with $\mathrm{t}^{0.65}$, whereas the correlation coefficients (Table 1) were > 0.94, indicating that the release of TAM can be described using particle diffusion-controlled model. In spite, the release from RIT was less than RIIT in both of the dissolution medium (Table 1), TAM release profile was very fast in initial period. So, the application of thin diffusion film could be helpful in controlling that release. 
Table 1: Parameters of tiaramide release from its resinates.

\begin{tabular}{|c|c|c|c|c|c|c|c|}
\hline \multirow[t]{2}{*}{ Resinate } & \multirow{2}{*}{$\begin{array}{l}\text { Dissolution } \\
\text { medium }\end{array}$} & \multirow{2}{*}{$\begin{array}{c}\mathrm{K} \times 10^{2} \\
\left(\min ^{-0.65}\right)\end{array}$} & \multirow[t]{2}{*}{$\mathrm{r}$} & \multicolumn{4}{|c|}{$\begin{array}{c}\text { Drug released (\%) at different } \\
\text { times (min) }\end{array}$} \\
\hline & & & & 5 & 10 & 15 & 20 \\
\hline RIT & $0.1 \mathrm{~N} \mathrm{HCl}$ & 5.2 & 0.998 & 42.69 & 45.7 & 49.05 & 53.67 \\
\hline RIIT & $0.1 \mathrm{~N} \mathrm{HCl}$ & 13.1 & 0.944 & 67.8 & 78.1 & 85.8 & 87.6 \\
\hline RIT & $\mathrm{pH} 7.4$ & 5.8 & 0.983 & 51.97 & 57.77 & 63.2 & 66.7 \\
\hline RIIT & $\mathrm{pH} 7.4$ & 37.3 & 0.949 & 75.25 & 80.03 & 82.72 & 85.4 \\
\hline
\end{tabular}

r: correlation coefficient; K: dissolution rate constant.

\section{Microencapsulation of TAM resinates \\ TAM resinates were \\ $0.1 \mathrm{~N} \mathrm{HCl}$. The results were in consistence with TAM release from uncoated resinates.} microencapsulated using modified emulsion solvent evaporation technique using cellulose acetate butyrate $(\mathrm{CAB})$ as a coating material at 3:1 resinates: $\mathrm{CAB}$ ratio. The percentage $(\mathrm{w} / \mathrm{w})$ of microencapsulation efficiency for microcapsules $M$ (RI/TAM) prepared using RI/TAM was $63.4 \pm 3.54$ while that $[\mathrm{M}$ (RII/TAM)] prepared using RIIT was $66.2 \pm 4.61$.

Figure 9 demonstrates scanning electron micrographs for microcapsules M (RI/TAM) with different magnification. The microcapsules appeared spherical in shape with absence of aggregates. The high magnification displayed smooth surface without crystals of the drug.

\section{Release study from microcapsules}

In general the release from the microencapsulated resinates was retarded and slower than from resinates (Fig. 10). The release from M (RII/TAM) was faster than from M (RI/TAM). The release in phosphate buffer ( $\mathrm{pH}$ 7.4) was faster than that in

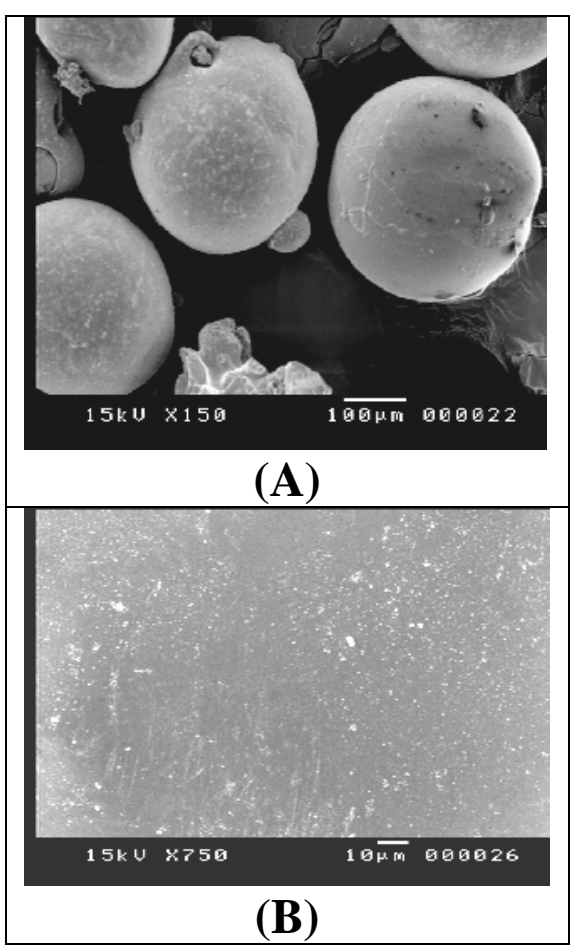

Fig. 9: Scanning electron micrographs for microcapsules of RI/TAM [M (RI/TAM)] with different magnification: (A) X 150, (B) X 750. 


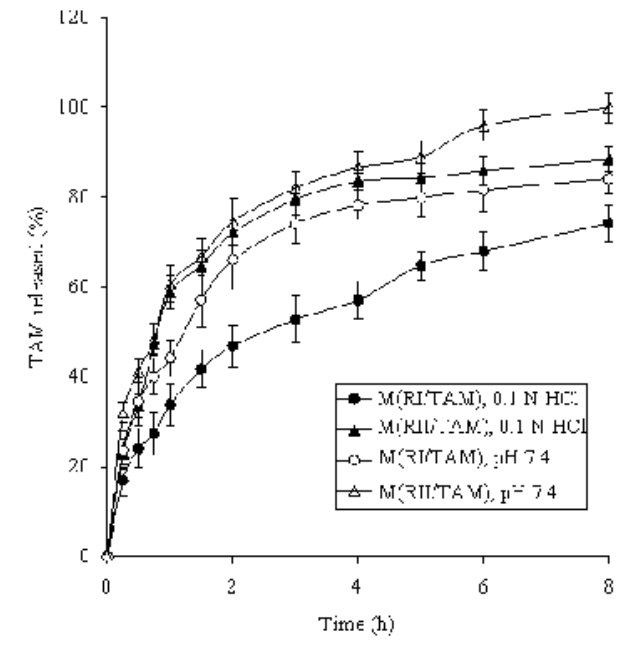

Fig. 10: Dissolution rate for the microencapsulated resinates in $0.1 \mathrm{~N} \mathrm{HCl}$ (closed symbols) or phosphate buffer ( $\mathrm{pH}$ 7.4) (open symbols): Microcapsules of RI/TAM [M(RI/TAM)]; Microcapsules of RII/TAM [M(RII/TAM)]. Error bars indicates $\mathrm{SD}, \mathrm{n}=3$.
The release data were examined according to the common kinetic models (zero-order, first-order, and Higuchi square root model). The release rate constants $(\mathrm{K})$ corresponding to each mechanism and the correlation coefficients (r) are depicted (Table 2). Since, the selection of the best-fit kinetic based on the correlation coefficients ( $r$ ) was difficult, TAM release data were analyzed through $60 \%$ released using the Ritger and Peppas' equation. ${ }^{24}$ The value of kinetic exponent $n$ defines the mechanism of drug release. $^{28}$ Table 2 comprises the values of (n) and the correlation coefficients (r) extracted from Ritger and Peppas' equation. ${ }^{24}$ High correlation coefficients were obtained $(\mathrm{r} \searrow 0.98)$ and values of $(\mathrm{n})$ were found in the range of 0.406 to 0.516 suggesting a Fickian diffusion mechanism was operating. ${ }^{28}$

Table 2: Kinetic parameters of tiaramide release from its microencapsulated resinates.

\begin{tabular}{||c|c|c|c|c|c|c|c|c|c||}
\hline \multirow{2}{*}{ Samples } & \multirow{2}{*}{$\begin{array}{c}\text { Dissolut- } \\
\text { ion } \\
\text { medium }\end{array}$} & \multicolumn{2}{|c|}{ Zero-order } & \multicolumn{2}{|c|}{ First-order } & \multicolumn{2}{|c|}{$\begin{array}{c}\text { Higuchi 's } \\
\text { model }\end{array}$} & \multicolumn{2}{|c|}{$\begin{array}{c}\text { Ritger and } \\
\text { Peppas } \\
\text { equation }\end{array}$} \\
\cline { 3 - 13 } & $\mathrm{r}$ & $\begin{array}{c}\mathrm{K}_{0} \\
(\% / \mathrm{h})\end{array}$ & $\mathrm{r}$ & $\begin{array}{c}\mathrm{K}_{1} \mathrm{X} 10^{-2} \\
\left(\mathrm{~h}^{-1}\right)\end{array}$ & $\mathrm{r}$ & $\begin{array}{c}\mathrm{K}_{\mathrm{h}} \\
\left(\% \mathrm{~h}^{-0.5}\right)\end{array}$ & $\mathrm{r}$ & $\mathrm{n}$ \\
\hline MRI & $0.1 \mathrm{~N} \mathrm{HCl}$ & 0.95 & 7.11 & 0.98 & 14.7 & 0.99 & 24.72 & 0.996 & 0.472 \\
\hline MRII & $0.1 \mathrm{~N} \mathrm{HCl}$ & 0.90 & 7.34 & 0.93 & 24.2 & 0.93 & 27.3 & 0.978 & 0.521 \\
\hline MRI & $\mathrm{pH} \mathrm{7.4}$ & 0.88 & 7.42 & 0.94 & 20.7 & 0.96 & 26.8 & 0.996 & 0.466 \\
\hline MRII & $\mathrm{pH} \mathrm{7.4}$ & 0.91 & 8.9 & 0.98 & 43.3 & 0.97 & 28.81 & 0.992 & 0.406 \\
\hline
\end{tabular}

r: correlation coefficient; $\mathrm{K}$ : dissolution rate constant; $\mathrm{n}$ : kinetic exponent 


\section{Anti-inflammatory studies}

Inhibitory activity of tiaramide (TAM), uncoated resinates (RI/TAM) and its microencapsulated resinates [M (RI/TAM)], on the swelling of carrageenan-induced rat hind paw edema is demonstrated in Figure 11. The experiment was conducted to evaluate the duration of action of TAM in form of microcapsules in comparison with the uncoated resinates or the pure drug. A peak inhibition of edema of about $42.6 \%$ was observed after $1 \mathrm{~h}$ for rats treated with TAM alone. Tsurumi et al. ${ }^{25}$ found that the values of percent inhibition were about $20 \%$ and $40 \%$ in carrageen-induced rat paw edema receiving tiaramide hydrochloride as $100 \mathrm{mg} / \mathrm{kg}$ and $200 \mathrm{mg} / \mathrm{kg}$ respectively. The reduced effectiveness observed with TAM powder during the late phase of carrageenan edema could be due to the drug's short duration of action. Value of peak inhibition (39.5\%) appeared after $3 \mathrm{~h}$ for rats received resinates. However, there was insignificant difference during the late phase of carrageenin edema (5-7 h) between the rats treated with TAM alone or TAM with resinate. For rats receiving $200 \mathrm{mg} / \mathrm{kg}$ as pure TAM and $\mathrm{M}$ (RI/TAM) at 1:1 ratio, the peak inhibition (\%) was 35.5 and occurred after $5 \mathrm{~h}$. The delayed peak of antiinflammatory response might be due to the delayed absorption of the TAM from the microcapsules fraction. The inhibition continued at higher level for $7 \mathrm{~h}$ than when using TAM alone or TAM with resinate. At $5 \mathrm{~h}, 6 \mathrm{~h}$ and
$7 \mathrm{~h}$ the group of rats administered TAM with M (RI/TAM) showed higher inhibition percent than that administered TAM powder alone or with resinates. At $5 \mathrm{~h}$ the differences was not significant at 5\% level of significance. But, at $6 \mathrm{~h}(\mathrm{p}<0.05)$ and $7 \mathrm{~h}(\mathrm{p}<0.01)$, the differences were significant and highly significant respectively. These results indicated that the presence of the resinates in the microencapsulated form prolonged TAM's duration of action.

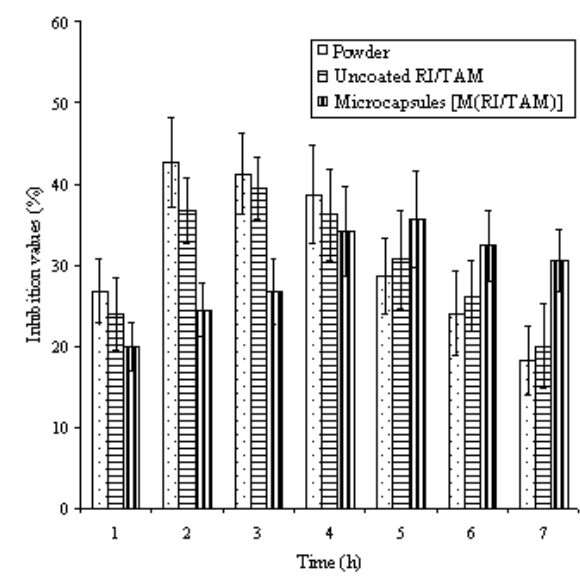

Fig. 11: Inhibitory activity of tiaramide powder, uncoated resinate (RI/TAM) and its microencapsulated resinate $[\mathrm{M}$ (RI/TAM], given orally, on the swelling of carrageenaninduced rat hind paw edema. Error bars indicates $\mathrm{SD}, \mathrm{n}=5$.

\section{Conclusion}

Tiaramide hydrochloride is a NSAID that has been given orally up to three times daily for the relief of pain, inflammation or treatment of 
bronchial asthma. TAM was converted to amorphous form through formation of the resinates according to DSC, XRD and SEM. In spite of this form, TAM resinate gave slower release than TAM powder or the physical mixtures. In vitro release data prevailed that the microencapsulation of resinates prolonged TAM release. Moreover, the inhibition activity of the microcapsules on the paw edema showed longer duration than powder of TAM or resinates. These cationexchange resins, as a formulation tool, can be of great value in developing new formulations for controlling TAM release.

\section{REFERENCES}

1- S. Borodkin. Ion Exchange Resins and Sustained Release. In The Encyclopedia of Pharmaceutical Technology; J. Swarbrick, J. C. Boylan, Eds. New York: Marcel Dekker, Inc; 8 (1993), pp. 203-216.

2- S. Borodkin and D. P. Sundberg, J. Pharm. Sci., 60, 1523 (1971).

3- G. M. Burke, R. W. Mendes and S. S. Jambhekar., Drug Dev. Ind. Pharm., 12, 713 (1986).

4- W. J. Irwin, K. A. Belaid and H. O Alpar, ibid., 13, 2047 (1987).

5- K. E Ogger, C. Noory, J. Gabay, V. P. Shah and J. P. Skelly, Pharm. Technol., 9, 84 (1991).

6- M. Sriwongjanya and R. Bodmeier, Eur. J. Pharm. Biopharm., 46, 321 (1998).

7- Y. N. Nujoma and C. J. A Kim, J. Pharm. Sci., 85, 1091 (1996).
8- R. G. Huang, J. B. Schwartz and C. M. Ofner $3^{\text {rd }}$, Pharm. Dev. Technol., 4, 107 (1999).

9- M. Sriwongjanya and R. Bodmeier, Int. J. Pharm., 158, 29 (1997).

10- M. Cuna,, J. L. V. Jato and D. Torres, ibid., 199, 151 (2000).

11- H. Ichikawa, K. Fujioka, M. C. Adeyeye and Y. Fukumori, ibid., 216, 67 (2001).

12- Y. Raghunanthan, L. Amsel, O. N. Hinsvark and W. J. Bryant, J. Pharm. Sci., 70, 379 (1981).

13- W. Betty, P. Michael, V. Dokuzovic and V. Lam, US patent 6001 392. December 14 (1999).

14- C. Imtiaz., K. Patricia, R. Edward and S. Joel, US patent 4 999 189. March 12, (1991).

15- A. Halder, S. Mukherjee and B. Sa, J. Microencapsul., 22, 67 (2005).

16- T. Takashima, T. Ono, M. Ohtsuka, J. Mori and S. Kumada, Arezneim-Forsch./Drug Res., 29, 903 (1979).

17- K. Tsurumi, Y. Hiramatsu, M. Nozaki, M. Hayashi and $\mathrm{H}$. Fujimura, ibid., 22, 724 (1972).

18- K. E. Berkin and J. W. Kerr, Br. J. Clin. Pharmacol. 14, 505 (1982).

19- K. Noda, H. Noguchi, M. Okui, K.Tada and Y. Morimoto, J. Kozatani, Arezneim-Forsch./ Drug Res., 22, 732 (1972).

20- P. Akkaramongkolporn, E. Yonemochi and K. Terada, Chem. Pharm. Bull., 48, 231 (2000). 
21- T. Pongjanyakul, A. Priprem, P. Chitropas and S Puttipipatkhachorn. AAPS Pharm. Sci.Tech., 6, 190 (2005).

22- E. Mikami, T. Goto, T. Ohno, and Y. Miyazaki, Journal of Liquid Chromatography \& Related Technologies, 23, 705 (2000).

23- R. Bhaskar, R. S. R. Murthy, B. D. Miglani and K. Viswanathan, Int. Pharm., 28, 59 (1986).

24- P. L. Ritger and N. A. Peppas, J. Controlled Release, 5, 23 (1987).
25- K. Tsurumi, Y. Hiramatsu, M. Nozaki, M. Hayashi and $\mathrm{H}$. Fujimura, Arzneim.-Forsch./ Drug Res., 22, 716 (1972).

26- P. Akkaramongkolporn, K. Terada and E. Yonemochi, Comm. Drug Dev. Ind. Pharm., 27, 359 (2001).

27- L. S. Porubcan, C. J. Serna, J. L. White and S. L. Hem, J. Pharm. Sci., 67, 1081 (1978).

28- G.W. Sinclair and N. A. Peppas, J. Membr. Sci., 17, 329 (1984). 